\title{
Analysis of plant growth-promoting properties of Bacillus amyloliquefaciens UCMB5113 using Arabidopsis thaliana as host plant
}

\author{
Shashidar Asari ${ }^{1}$ - Danuše Tarkowská ${ }^{2} \cdot$ Jakub Rolčík $^{2}$ • Ondřej Novák ${ }^{2}$. \\ David Velázquez Palmeroo ${ }^{1} \cdot$ Sarosh Bejai $^{1} \cdot$ Johan Meijer $^{1}$
}

Received: 10 December 2015/Accepted: 2 August 2016/Published online: 19 August 2016

(C) The Author(s) 2016. This article is published with open access at Springerlink.com

\begin{abstract}
Main conclusion This study showed that Bacillus amyloliquefaciens UCMB5113 colonizing Arabidopsis roots changed root structure and promoted growth implying the usability of this strain as a novel tool to support sustainable crop production.
\end{abstract}

Root architecture plays a crucial role for plants to ensure uptake of water, minerals and nutrients and to provide anchorage in the soil. The root is a dynamic structure with plastic growth and branching depending on the continuous integration of internal and environmental factors. The rhizosphere contains a complex microbiota, where some microbes can colonize plant roots and support growth and stress tolerance. Here, we report that the rhizobacterium Bacillus amyloliquefaciens subsp. plantarum UCMB5113 stimulated the growth of Arabidopsis thaliana Col-0 by increased lateral root outgrowth and elongation and roothair formation, although primary root elongation was inhibited. In addition, the growth of the above ground tissues was stimulated by UCMB5113. Specific hormone

Electronic supplementary material The online version of this article (doi:10.1007/s00425-016-2580-9) contains supplementary material, which is available to authorized users.

Johan Meijer

johan.meijer@slu.se

1 Department of Plant Biology, Uppsala Biocenter, Swedish University of Agricultural Sciences and Linnéan Center for Plant Biology, Box 7080, S75007 Uppsala, Sweden

2 Laboratory of Growth Regulators, Centre of the Region Haná for Biotechnological and Agricultural Research, Institute of Experimental Botany ASCR and Palacký University, Šlechtitelů 11, CZ-783 71 Olomouc, Czech Republic reporter gene lines were tested which suggested a role for at least auxin and cytokinin signaling during rhizobacterial modulation of Arabidopsis root architecture. UCMB5113 produced cytokinins and indole-3-acetic acid, and the formation of the latter was stimulated by root exudates and tryptophan. The plant growth promotion effect by UCMB5113 did not appear to depend on jasmonic acid in contrast to the disease suppression effect in plants. UCMB5113 exudates inhibited primary root growth, while a semi-purified lipopeptide fraction did not and resulted in the overall growth promotion indicating an interplay of many different bacterial compounds that affect the root growth of the host plant. This study illustrates that beneficial microbes interact with plants in root development via classic and novel signals.

Keywords Beneficial bacteria - Biocontrol - Growth promotion $\cdot$ Phytohormones $\cdot$ Rhizosphere $\cdot$ Root structure

\author{
Abbreviations \\ CK Cytokinin \\ GA Gibberellins \\ ISR Induced systemic resistance \\ JA Jasmonic acid \\ PGPR Plant growth-promoting rhizobacteria
}

\section{Introduction}

Roots support plants physically by anchoring and chemically through the acquisition of nutrients and water from soil. The root architecture adopts the most suitable structure depending on plant needs and is influenced by various environmental stimuli (Rogers and Benfey 2014; Pacifici et al. 2015). The root is a complex organogenic structure, 
where information from other plant tissues is integrated together with data from probing of the local soil environment in order for the plant to develop an appropriate root architecture (Pacifici et al. 2015; Rogers and Benfey 2014). A wide range of nutrients and signaling molecules are exuded from roots directing the plant-microbe interactions (Badri and Vivanco 2009). Soil houses a complex microbiota, including strains, that can be beneficial or detrimental to plants. Certain organic compounds exuded act as chemical signals for microbes by stimulating colonization through chemotaxis (Alexandre 2010). Many rhizobacteria can thus associate with plants and ideally promote plant growth and fitness and are referred to as plant growthpromoting rhizobacteria (PGPR) (Lucy et al. 2004). The associated microbes may affect root morphogenesis (Persello-Cartieaux et al. 2003), and many studies suggest that the acceleration of plant growth by PGPR involves phytohormone modulation.

Plant development and root architecture are dependent on the level of hormones and nutrients, where PGPR can have a substantial influence (Vacheron et al. 2013). PGPR can support nutrient uptake, e.g., solubilize phosphorous and iron, which can stimulate initiation, elongation, and development of lateral roots (Ortíz-Castro et al. 2009). Many soil microorganisms produce auxins, which include indole-3-acetic acid (IAA) and indole-3-butyric acid that can support plant growth (Martínez-Morales et al. 2003; Spaepen et al. 2007). It has been reported that PGPR producing IAA stimulated growth of various plants, such as sugar beet (Loper and Schroth 1986), Brassica juncea (Asghar et al. 2002), and wheat (Khalid et al. 2004). Cytokinins (CKs) are involved in plant cell division, shoot formation, primary root growth, and callus formation and are utilized in shoot and root meristems (Howell et al. 2003). It is known that certain rhizobacteria, such as Bacillus megaterium, can produce CKs that stimulate host plants (Ortíz-Castro et al. 2009). Gibberellins (GA) are another group of plant hormones that influence various developmental processes in plants, including seed germination, stem elongation, flowering, sex expression, and fruit formation (Claeys et al. 2014). It has been shown that PGPR may produce GA (Bastian et al. 1998; GutierrezManero et al. 2001; Joo et al. 2004) that stimulate plant growth. Brassinosteroids are steroid hormones that are essential to regulate plant growth and development and have been recognized as one of the major plant hormones (Zhu et al. 2013).

Use of microorganisms as environmental friendly strategies to support crop production has great potential. A lot of attention has been given to microorganisms that confer disease suppression (Choudhary and Johri 2009) referred to as priming of induced systemic resistance (ISR)
(Pieterse et al. 2012). We have identified Bacillus amyloliquefaciens strains with ability to suppress common Brassica fungal phytopathogens (Danielsson et al. 2007; Sarosh et al. 2009) and support abiotic stress tolerance (Abd El-Daim et al. 2014). During such studies, we frequently observed growth stimulation of plants, including oilseed rape, wheat, and Arabidopsis thaliana. Microorganisms that both stimulate plant growth and stress management provide a good model system to study the mechanisms supporting these different properties. The aim of this work was to characterize plant growth promotion properties of UCMB5113 using A. thaliana Col-0 as host plant. Use of an axenic model system allowed studies of effects on root system architecture, where mutants and reporter lines enabled an approach to study the role for some common signals and how this correlated with changes in the root system.

\section{Materials and methods}

\section{Bacterial growth conditions and plant inoculation}

The Bacillus amyloliquefacienes subsp. plantarum UCMB5113 (UCM, Kiev, Ukraine) was maintained on LB medium. A colony was inoculated in LB and grown overnight at $180 \mathrm{rpm}, 28^{\circ} \mathrm{C}$. Next day, the bacterial culture was diluted to $10^{7} \mathrm{cfu} \mathrm{ml}^{-1}$. Surface sterilized Arabidopsis thaliana Col-0 seeds (NASC, Nottingham, UK) were germinated on $0.2 \times$ Murashige-Skoog (MS) medium, including vitamins (MS0222, Duchefa, Netherlands), $0.6 \%$ Bacto agar plates. Later, plates were shifted to a growth chamber at $22{ }^{\circ} \mathrm{C}$ with $16 / 8 \mathrm{~h}$ photoperiod. After 5 days, seedlings were transplanted to new square petri dishes containing $0.2 \times \mathrm{MS}, 0.8 \%$ Bacto agar. Aliquots of usually 10 or $25 \mu$ l (corresponding to $2 \times 10^{7}$ or $\left.5 \times 10^{7} \mathrm{cfu}\right)$ of Bacillus UCMB5113 were inoculated at a distance of $3 \mathrm{~cm}$ from the root tip, and plates were placed vertically in a growth chamber for 6 days (four plants in each plate with $2.5 \mathrm{~cm}$ inter distance). After 6 days, the root and shoot was separated and fresh and dry biomass determined. The experiments were repeated three times. Bacterial colonization of roots was verified by tissue printing using filters replicas on LB plates and analysis as described (Johansson et al. 2014).

Bacterial exudates were collected from day 2 to 6 of UCMB5113 grown in LB and tested on 1-week-old $A$. thaliana seedlings. Bacterial exudates and/or auxin were dropped on filter paper discs at $3 \mathrm{~cm}$ distance from the main root tip. Six days' post-inoculation images were taken with a digital camera. 


\section{Root architecture}

Digital images of petri dishes of A. thaliana seedlings $(n=16)$ were taken using a digital camera positioned at the same distance from the samples. The Rhizo software (Armengaud et al. 2009) was used to measure the primary root and the lateral roots. For root-hair analysis, digital images were taken using a stereo microscope and a section of $2 \mathrm{~cm}$ from the primary root tip used for analysis by image $\mathrm{J}$ (Schneider et al. 2012) to determine the number of root hairs.

\section{Auxin and CK production by $B$. amyloliquefacienes UCMB5113}

Production of IAA by Bacillus UCMB5113 was determined as described previously (Glickmann and Dessaux 1995). Bacterial exudates were collected from day 0 to 4 of UCMB5113 grown in LB or Arabidopsis root exudates (10\% final concentration) with or without tryptophan $\left(0.2 \mathrm{mg} \mathrm{ml}^{-1}\right)$. Production of CKs by Bacillus UCMB5113 was determined in bacterial exudates collected from day 0 to 5 of UCMB5113 grown in LB with or without oilseed rape root exudates. Quantitation of $\mathrm{CK}$ metabolites was performed according to the modified method described by Antoniadi et al. (2015) based on Svačinová et al. (2012).

\section{Isolation of root exudates}

Arabidopsis thaliana Col-0 seeds were surface sterilized and germinated in a $500 \mathrm{ml}$ flask containing $0.5 \times \mathrm{MS}$ medium at $22{ }^{\circ} \mathrm{C}, 16 / 8 \mathrm{~h}$ photoperiod with shaking for 10-14 days. The aqueous phase exudates were lyophilized, resuspended in sterile water, and sterile filtered before use.

\section{Analysis of reporter lines}

The expression of DR5:GFP and Arr5:Gus plants and response to UCMB5113 was studied 1-6 days post-inoculation and using pieces of the primary or lateral root $(2 \mathrm{~cm}$ from the root tip) that was detached and placed on a glass slide. Fluorescent images were taken at 6 dpi with a Zeiss confocal scanning microscope 780 (Zeiss, Jena, Germany). Green fluorescent protein was excited at $488 \mathrm{~nm}$ and detected at $493-530 \mathrm{~nm}$. The images were analyzed using the built-in Zen2011 software. Cyclin1:Gus (Donnelly et al. 1999) 5-day-old seedlings were inoculated with UCMB5113 and 6 days later analyzed for dividing cells in the proliferation zone of the primary root tip.

\section{Phytohormone analysis of plant tissues}

Five-day-old seedlings were co-cultivated on $0.2 \times \mathrm{MS}$ agar plate with Bacillus UCMB5113 for 6 days. The root and shoot were then separated for quantitative hormone analysis performed according to following protocols. Samples were analyzed for GA content according to Urbanová et al. (2013) with modifications. Root and shoot samples (10 $\mathrm{mg}$ fresh weight) were homogenized in $2 \mathrm{ml}$ polypropylene tubes with $1 \mathrm{ml}$ of $80 \%(\mathrm{v} / \mathrm{v})$ acetonitrile containing $5 \%(\mathrm{v} / \mathrm{v})$ formic acid using an MM 301 mixer mill (Retsch, Haan, Germany) at a frequency of $27 \mathrm{~Hz}$ for 3 min after adding $2 \mathrm{~mm}$ zirconium oxide beads with $1 \mathrm{ml}$ of $80 \%(\mathrm{v} / \mathrm{v})$ acetonitrile containing $5 \%(\mathrm{v} / \mathrm{v})$ formic acid and 19 internal GA standards $\left.\left({ }^{2} \mathrm{H}_{2}\right] \mathrm{GA}_{1},{ }^{2} \mathrm{H}_{2}\right] \mathrm{GA}_{3}$, $\left[{ }^{2} \mathrm{H}_{2}\right] \mathrm{GA}_{4}, \quad\left[{ }^{2} \mathrm{H}_{2}\right] \mathrm{GA}_{5}, \quad\left[{ }^{2} \mathrm{H}_{2}\right] \mathrm{GA}_{6}, \quad\left[{ }^{2} \mathrm{H}_{2}\right] \mathrm{GA}_{7}, \quad\left[{ }^{2} \mathrm{H}_{2}\right] \mathrm{GA}_{8}$, $\left[{ }^{2} \mathrm{H}_{2}\right] \mathrm{GA}, \quad\left[{ }^{2} \mathrm{H}_{2}\right] \mathrm{GA}_{12}, \quad\left[{ }^{2} \mathrm{H}_{2}\right] \mathrm{GA}_{12}$ ald, $\left[{ }^{2} \mathrm{H}_{2}\right] \mathrm{GA}_{15}$, $\left[{ }^{2} \mathrm{H}_{2}\right] \mathrm{GA}_{19},\left[{ }^{2} \mathrm{H}_{2}\right] \mathrm{GA}_{20},\left[{ }^{2} \mathrm{H}_{2}\right] \mathrm{GA}_{24},\left[{ }^{2} \mathrm{H}_{2}\right] \mathrm{GA}_{29},\left[{ }^{2} \mathrm{H}_{2}\right] \mathrm{GA}_{34}$, $\left[{ }^{2} \mathrm{H}_{2}\right] \mathrm{GA}_{44},\left[{ }^{2} \mathrm{H}_{2}\right] \mathrm{GA}_{51}$, and $\left.\left[{ }^{2} \mathrm{H}_{2}\right] \mathrm{GA}_{53}\right)(\mathrm{OlChemIm}$, Olomouc, Czech Republic) The tubes were then placed in a $4{ }^{\circ} \mathrm{C}$ fridge and extracted overnight with constant stirring at a frequency of $15 \mathrm{rpm}$. The homogenates were centrifuged for $10 \mathrm{~min}$ at $4{ }^{\circ} \mathrm{C}$. Supernatants were further purified using mixed-mode anion exchange cartridges (Waters, Milford, MA, USA) and analyzed by ultra highperformance chromatography (Acquity UPLC ${ }^{\mathrm{TM}}$ System; Waters) coupled to triple-stage quadrupole mass spectrometer (Xevo ${ }^{\circledR}$ TQ MS; Waters) equipped with an electrospray ionization (ESI) interface. GA were detected using the multiple-reaction-monitoring mode based on the transition of the precursor ion $[\mathrm{M}-\mathrm{H}]^{-}$to the appropriate product ion. Data were acquired and processed by the Masslynx 4.1 software (Waters), and GA levels were calculated using the standard isotope-dilution method (Rittenberg and Foster 1940).

The auxin analysis has been performed as described earlier by Pěnčík et al. (2009) with some modifications. Briefly, frozen barley seed samples (5 $\mathrm{mg}$ of fresh weight) were homogenized in $2 \mathrm{ml}$ polypropylene tubes and extracted for 5 min with $1 \mathrm{ml}$ of cold phosphate buffer $(50 \mathrm{mM} ; \quad \mathrm{pH} \quad 7.0)$ containing $0.02 \%$ sodium diethyldithiocarbamate and $\left[{ }^{2} \mathrm{H}_{5}\right] \mathrm{IAA}$ as an internal standard. After centrifugation $\left(36,000 \times g ; 10 \mathrm{~min} ;+4{ }^{\circ} \mathrm{C}\right)$, each sample was transferred into a new Eppendorf tube, acidified with $1 \mathrm{M} \mathrm{HCl}$ to $\mathrm{pH} 2.7$ and subjected to a C8based solid-phase extraction, methylated with ethereal diazomethane, and subsequently purified by immunoaffinity extraction. The final analysis was done by ultra-HPLC (Acquity UPLC ${ }^{\mathrm{TM}}$ System) coupled to tandem mass spectrometer (Xevo ${ }^{\circledR} \mathrm{TQ} \mathrm{MS}$ ) equipped with the electrospray ionization (ESI) interface operating in the positive mode. Data were acquired and processed by the Masslynx 4.1 software, and IAA levels were calculated using the standard isotope-dilution method on the basis of auxin detection in multiple-reaction-monitoring mode.

For quantitative analysis of brassinosteroids, root and shoot samples of 25 and $50 \mathrm{mg}$ fresh weight, respectively, 
were sonicated for $5 \mathrm{~min}$ and extracted overnight with stirring in ice-cold $60 \%(\mathrm{w} / \mathrm{v})$ acetonitrile and $30 \mathrm{pmol}$ of $\left[{ }^{2} \mathrm{H}_{3}\right]$ brassinolide, $\left[{ }^{2} \mathrm{H}_{3}\right]$ castasterone, $\left[{ }^{2} \mathrm{H}_{3}\right] 24$-epi-brassinolide, and $\left[{ }^{2} \mathrm{H}_{3}\right] 24$-epi-castasterone as internal standards (OlChemIm). After centrifugation, samples were further purified on polyamide SPE columns (Supelco, Bellefonte, PA, USA) and then analyzed by ultra-HPLC (Acquity UPLC $^{\mathrm{TM}}$ System) coupled to tandem mass spectrometer (Xevo ${ }^{\circledR}$ TQ MS). The data were analyzed using the Masslynx 4.1 software, and brassinosteroid content was quantified using the standard isotope-dilution method based on the detection of analytes in multiple-reaction-monitoring mode.

\section{Test of crude lipopeptide compounds on plant growth and development}

Lipopeptide compounds were isolated from Bacillus UCMB5113 by a protocol described by Kim et al. (2004). Sterilized seeds were germinated on petri dishes containing $0.5 \times$ MS with $0.6 \%$ agar and incubated at $22{ }^{\circ} \mathrm{C}, 16 / 8$ light and dark photoperiod. One-week-old seedlings were transplanted on $0.5 \times$ MS with $0.8 \%$ agar on $10 \times 10 \mathrm{~cm}$ square plates and four seedlings on each plate with a distance of $2.5 \mathrm{~cm}$ between each seedling. The roots were coated with $5 \mu \mathrm{l}$ of $2.5 \mathrm{ng} \mathrm{ml}^{-1}$ isolated lipopeptide compounds, $5 \%$ methanol or water. The plates were incubated at $22{ }^{\circ} \mathrm{C}, 16 / 8$ light and dark photoperiod and placed vertically. Five days' post-inoculation of crude lipopeptide compounds, half the batch $(n=20)$, was moved to sterile soil (S-soil, Weibulls plant soil) with one plant per pot, and the remaining plants were allowed to grow further on MS agar plates. Growth was monitored after 10 days of crude lipopeptide compounds treatment of plants on agar plates and 12 days after on soil-transplanted plants. Flowering was recorded after 21 days, and the number of siliques and seed weight analyzed after 48 days on soil-transplanted plants.

\section{Statistical analysis}

Analysis for significance was calculated using ANOVA, all pairs, Tukey-Kramer HSD $(p<0.05)$.

\section{Results}

\section{Effect of UCMB5113 on plant growth and root system architecture}

The effect of plant growth-regulating substances and signaling mechanisms operating as a result of UCMB5113 colonization of $A$. thaliana Col-0 roots was tested in an axenic test system. Arabidopsis seedlings were grown vertically on $0.2 \times$ MS agar medium. Six days after inoculation with UCMB5113 characteristic changes in root architecture were observed with reorganized overall structure and growth avoidance through the bacterial zone (Fig. 1a-d). Significant increases in fresh weight of plant root and shoot were observed (Fig. 1d). The weight increase was dose dependent, rising 1.5- and 3-folds, and 0.2 - and 0.5 -folds in the presence of 10 and $25 \mu \mathrm{l}$ UCMB5113 for root and shoot, respectively. Interestingly, UCMB5113 had a profound effect on the root system architecture and caused almost a $50 \%$ reduction of primary root length but increased outgrowth and elongation of lateral roots, root hairs, and total root area compared to control plants (Fig. 1a-d). UCMB5113 does not seem to interfere with gravitropism, since turning the plate $90^{\circ}$ resulted in a gravitropic response of root tips, even though slightly retarded for the inoculated primary root tip. In addition, if plants were inoculated with UCMB5113 alongside with the root and after 1-3 days turned $90^{\circ}$, a gravitropic response was observed (results not shown). If not growth arrest of the primary root occurred, the root tip frequently seemed to grow either below bacteria into the agar or above in the air. The effect of bacterial dosage on plant growth parameters on Arabidopsis varied. For example, inoculation with $25 \mu \mathrm{l}$ UCMB5113 increased root fresh weight compared to $10 \mu \mathrm{l}$ of UCMB5113 inoculation, while the difference was smaller for lateral root formation, elongation, root-hair number, and root area (Fig. 1d).

Furthermore, we investigated the alteration of cell growth and cell proliferative zones in the primary root after inoculation with UCMB5113. The growth zone on the root tip consists of small dividing cells forming the meristem with more enlarged elongated cells differentiating into other cell types (Gaillochet et al. 2015). Similar overall cell organization of the root tip was observed in both UCMB5113 inoculated and control plants. However, the localization of the cell differentiation zone was closer to the root meristem region with the initiation of root hairs in inoculated plants compared to control plants (Fig. 1c). The analysis of cyclin1:Gus plants to measure the number of dividing cells in the primary root division zone found $45 \pm 26$ and $35 \pm 16$ cells $(n=25)$ for control and UCMB5113-treated seedlings, respectively. The difference was not statistically significant $(t$ test, $p=0.112, d f=39$ ).

From other studies, we got indications that UCMB5113 improved stress management involves plant jasmonic acid (JA) signaling. To elucidate the role of JA-dependent plant signaling for the growth promotion activity and altered plant development caused by UCMB5113, we used the signaling mutants coil-16, jarl, myb72, and nprl. The overall root morphology was fairly similar among the 
a

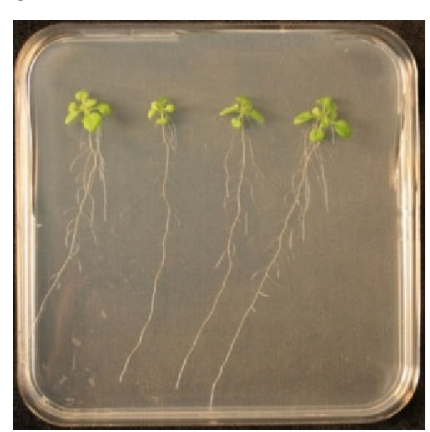

Control

b

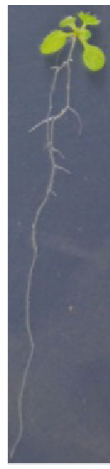

C

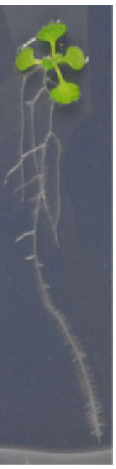

$10 \mu l$

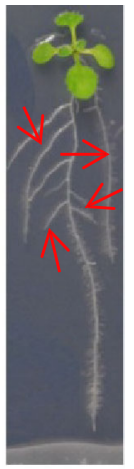

$25 \mu \mathrm{l}$

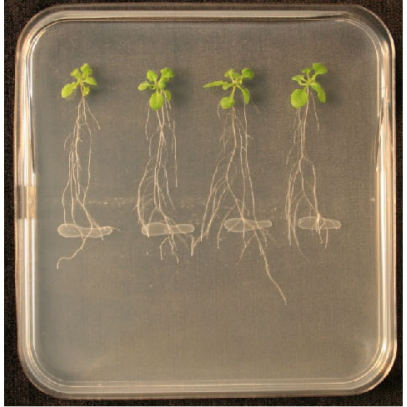

$10 \mu \mathrm{Bac}$

C

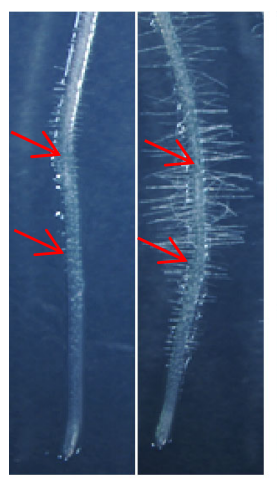

Bac

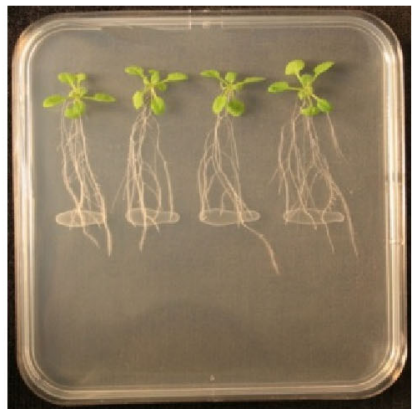

$25 \mu \mathrm{Bac}$

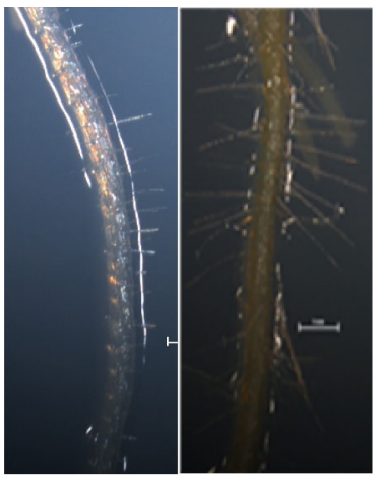

Bac
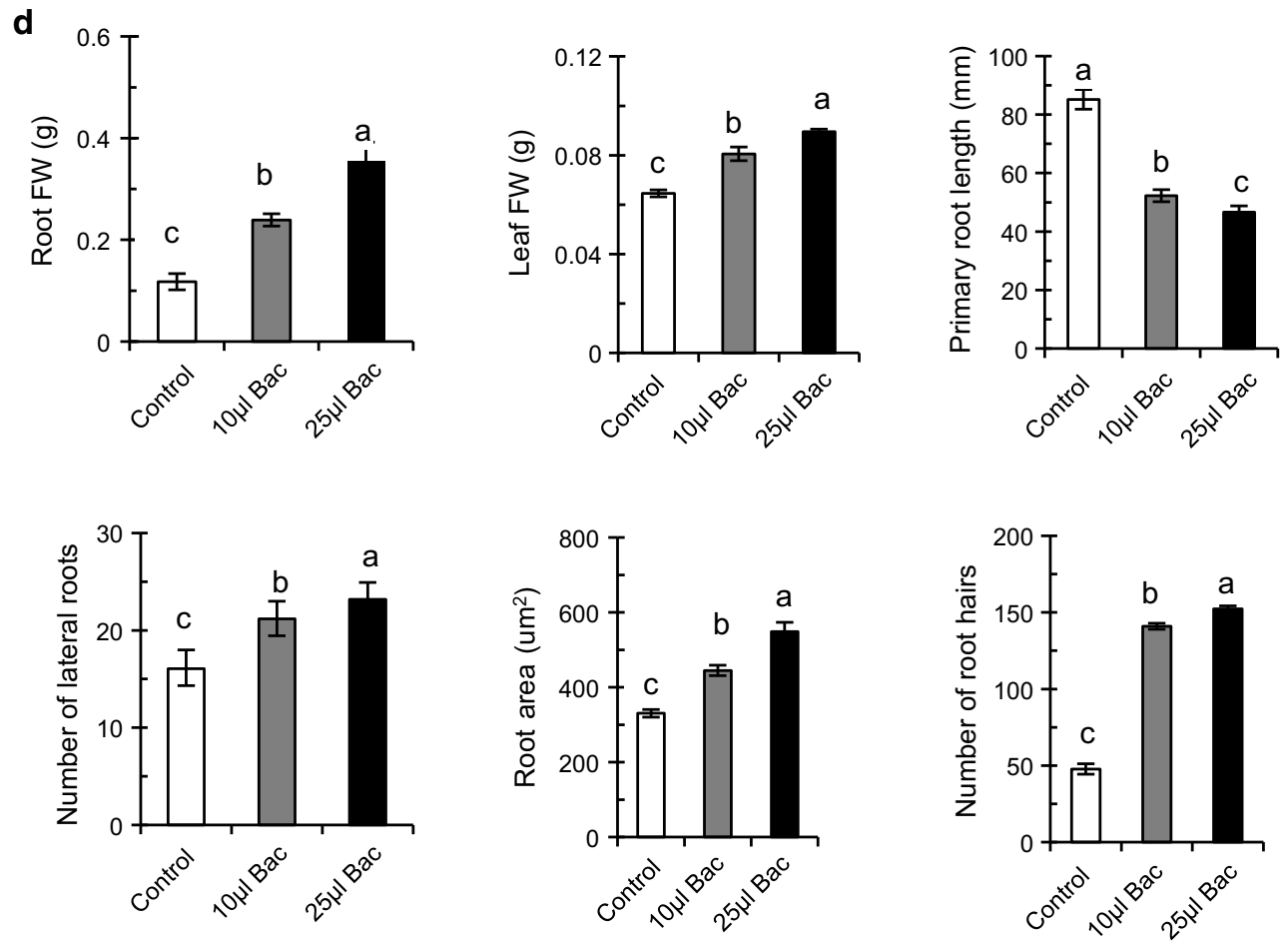
4Fig. 1 Effects of Bacillus amyloliquefacienes UCMB5113 on A. thaliana Col-0 seedlings. Five-day-old seedlings were placed vertically on $0.2 \times$ MS agar plates with $2.5 \mathrm{~cm}$ distance in between plants and treated with water, $10 \mu \mathrm{l}\left(2 \times 10^{7} \mathrm{cfu}\right)$ or $25 \mu \mathrm{l}\left(5 \times 10^{7} \mathrm{cfu}\right)$ UCMB5113 as a streak at $3 \mathrm{~cm}$ distance from the primary root of the seedlings. After 6 days of co-cultivation, the growth pattern of the whole root was analyzed. Overview of the growth promotion aspect of Bacillus treated plants (a), closeup pictures, where arrows indicate increased number of lateral roots (b) and the increased frequency of root hairs on primary and later roots and initiation of root hairs close to root tip after UCMB5113 inoculation (c). Root and shoot fresh weight and image analysis of primary root length, total number of lateral roots, and total root area carried out by the rhizo software (d). Values represent means and standard deviations $(n=16)$, where samples labelled with identical letters are not significant at $p<0.05$

different plants tested (Fig. 2a). However, the pattern of lateral root outgrowth and root hairs varied among the mutants (Fig. 2a, b). After 6 days of growth in the presence of UCMB5113, the primary root was arrested to $50 \%$ of control value for all plants, but UCMB5113 stimulated lateral roots, root hairs, and root area in all mutants as well as in wild-type plants (Fig. 2c).

\section{The effect of UCMB5113 on plant phytohormones}

Due to the effects on root architectures observed by UCMB5113 inoculation, it was relevant to test to which extent UCMB5113 affected plant growth-regulating substances, including phytohormones, such as auxins, GA, CKs and brassinosteroids. The expression and level of auxin were analyzed in roots and leaves of $A$. thaliana Col-0 plants after 6 days of bacterial inoculation. In plants inoculated with $25 \mu$ l UCMB5113, a significant fourfold increase of auxin in roots was observed compared to $10 \mu \mathrm{l}$ inoculated and control plants (Fig. 3a). However, similar levels of auxin were seen in leaves of inoculated and control plants (Fig. 3a). Furthermore, we examined the auxin expression in DR5:GFP Arabidopsis auxin response reporter plants. After 6 days of co-cultivation, high expression of $D R 5$ in the primary root tip and in lateral root meristem cells was observed in $25 \mu \mathrm{l}$ inoculated plants but less in $10 \mu \mathrm{l}$ inoculated and only in the zone of quiescent center of control plants (Fig. 3b). To study the potential production of auxin by UCMB5113, the bacteria were grown in LB or root exudates and the effect of supplementation with L-tryptophan was also examined. An increase of auxin production by UCMB5113 was observed from day 1 to 4 in the presence of root exudates, where the addition of tryptophan to the exudate further increased the levels of IAA (Fig. 3c). The amount of auxin remained at a similar level throughout the experimental period. Auxin production was also observed in the absence of root exudates for
UCMB5113 grown in LB with or without tryptophan, but the production of auxin was much lower and remained at a low level and without a stimulatory effect by tryptophan as observed for root exudates.

To analyze the effect of UCMB5113 on the levels of GAs in plants, Arabidopsis Col-0 root and leaves were analyzed separately after co-cultivation with UCMB5113 for 6 days. No significant difference of total endogenous GAs was observed in roots with only moderate tendency to increase in the presence of bacteria (Table 1). In contrast, the total GAs' content in leaves was reduced in UCMB5113 inoculated plants compared to untreated plants (Table 2). However, the level of different GA biosynthetic precursors, bioactive GAs, and their metabolite products varied in the presence or absence of UCMB5113 (Tables 1, 2).

Furthermore, we analyzed the potential changes in expression of CKs in planta using Arr5:Gus Arabidopsis lines as CK responsive and specific reporter plants (D'Agostino et al. 2000). After 6 days of co-cultivation, high expression of Arr5 in the primary and lateral root was observed in 10 and $25 \mu \mathrm{l}$ inoculated plants compared to the control indicative of elevated CK levels after UCMB5113 treatment (Fig. 4). To study the potential production of CKs by UCMB5113, the bacteria were grown in LB with or without root exudates. The LB medium contained many CKs, while the root exudate contained much less (Table 3). The presence of UCMB5113 rapidly increased the levels of CK bases and nucleotides, while the levels of CK ribosides and $O$-glucosides rapidly declined (Table 3). Effects on other CKs were small (for example, decreased levels of $N$ glucosides, results not shown). The effects of UCMB5113 on some Arabidopsis CK-signaling mutants were tested to study the role of exogenous CK production on plants. Increased root branching and leaf tissue was observed when $\operatorname{arrl}$ (deficient response regulator that acts in concert with other response regulators in CK signaling) and $\operatorname{cin} 1$ (defective in the induction of ethylene biosynthesis by CK) plants was grown in the presence of UCMB 5113 indicating some complementary effect (results not shown).

To investigate whether UCMB5113 inoculation could involve the regulation of steroid hormones in plant development and physiology, brassinosteroids were analyzed. After 6 days of growth in the presence of UCMB5113, the Arabidopsis shoot and root were analyzed (Fig. 5). In roots, brassinolide, castasterone, and teasterone levels were highest in $10 \mu \mathrm{l}$ UCMB5113-inoculated plants, while in leaves, the levels of castasterone and homocastasterone were highest for the $25 \mu \mathrm{l}$ inoculated plants, respectively. However, the level of different brassinosteroids in roots and shoot varied among the UCMB5113 treatments (Fig. 5). 
a

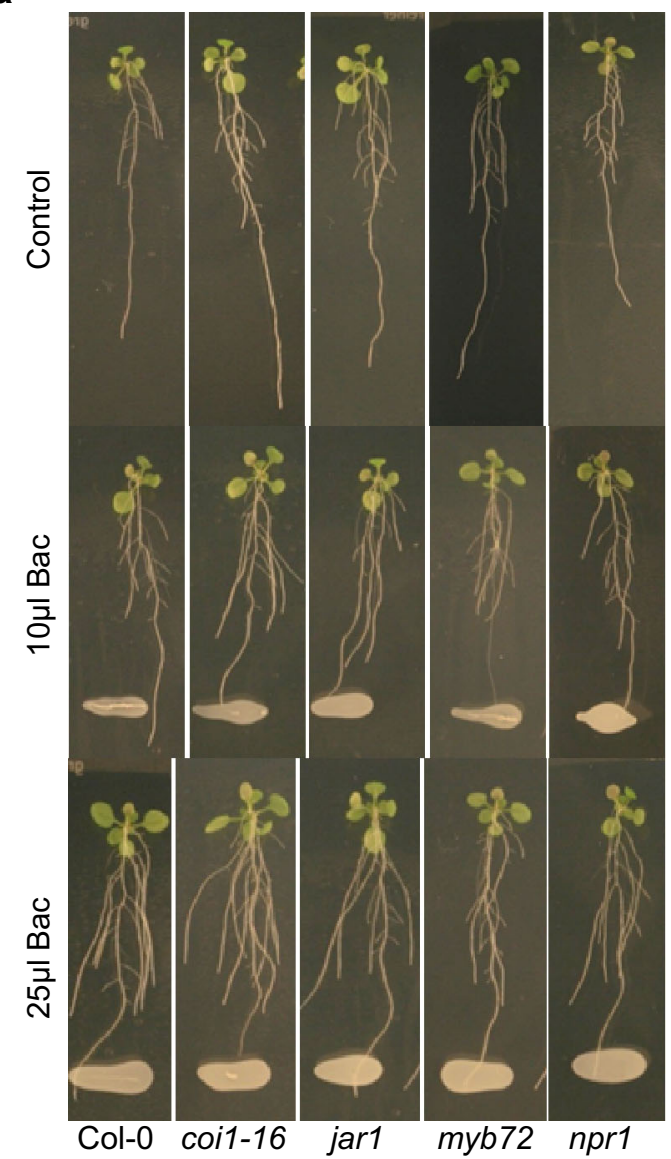

b
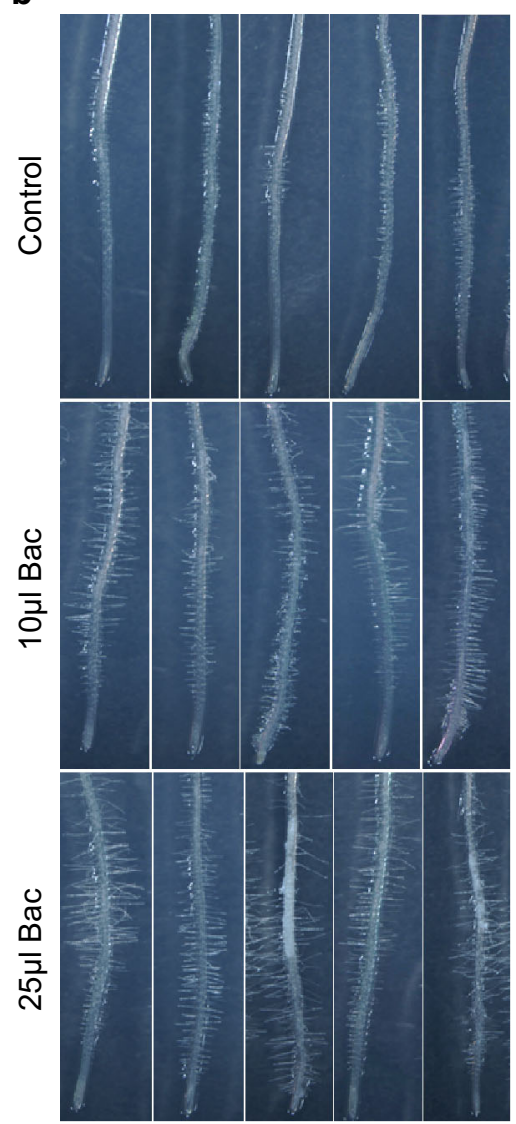

Col-0 coi1-16 jar1 myb72 npr1
C
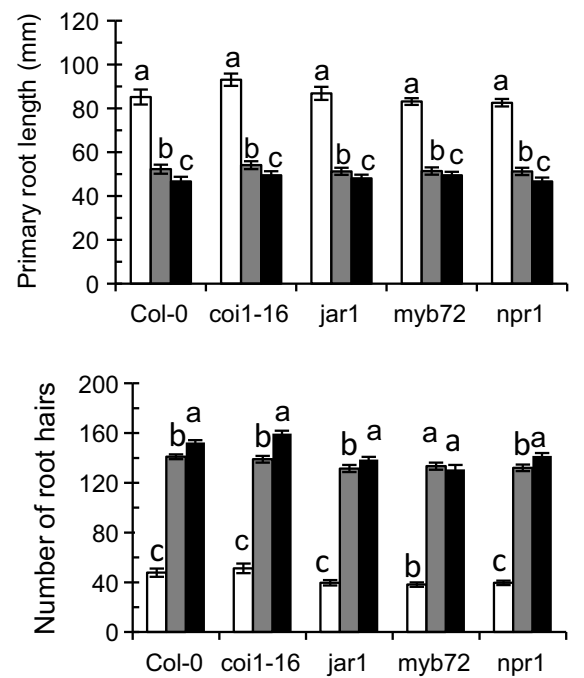

Fig. 2 Effects of Bacillus UCMB5113 on plant growth of some Arabidopsis signaling mutants. Five-day-old seedlings $(n=16)$ were lined up on $0.2 \times$ MS agar plates and treated with water or Bacillus UCMB5113 (3 cm distance from the main root tip). Six days later digital images were taken for the overall root analysis. a Overall pictures of water control, 10 or $25 \mu \mathrm{l}$ UCMB5113-treated plants. b Root hairs of control, 10 or $25 \mu \mathrm{l}$ UCMB5113-treated plants.
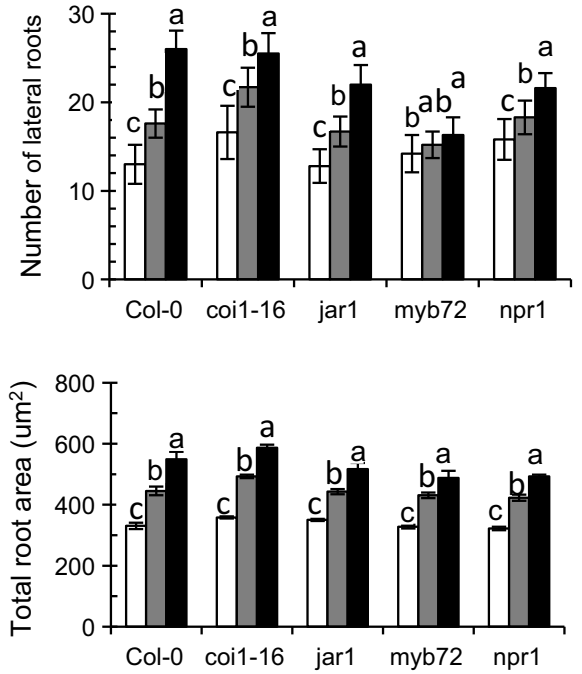

c Image analysis of control (white bars), $10 \mu \mathrm{l}$ (grey bars) or $25 \mu \mathrm{l}$ UCMB5113 (black bars) treated plants. Rhizo software was used to determine the primary and lateral root elongation, while root-hair number and total root area were determined with Image J. Values represent means and standard deviations $(n=16)$, where samples with the same letter are not significantly different at $p<0.05$ 
Fig. 3 Effect of auxin level in Arabidopsis root by UCMB5113 and culture filtrate. Five-day-old seedlings on $0.2 \times$ MS agar plates were treated with water or Bacillus

UCMB5113 and analyzed 6 days later. a Auxin analysis of indole-3-acetic acid (IAA) level in Arabidopsis roots and shoots. b Expression of auxin responsive DR5:GFP in primary roots or lateral roots. c Production of auxin by UCMB5113 monitored from day 0 to 4 in LB (diamonds) supplemented with tryptophan (squares), or root exudates (triangles) with tryptophan (circles), or tryptophan and root exudates but without

UCMB5113 (X). Results shown as mean and standard deviation of three samples a

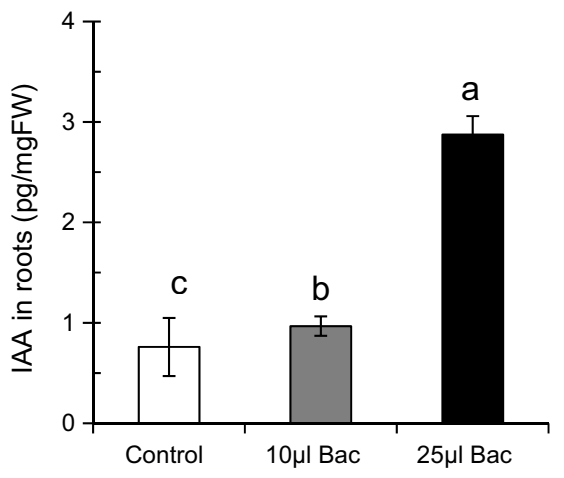

b

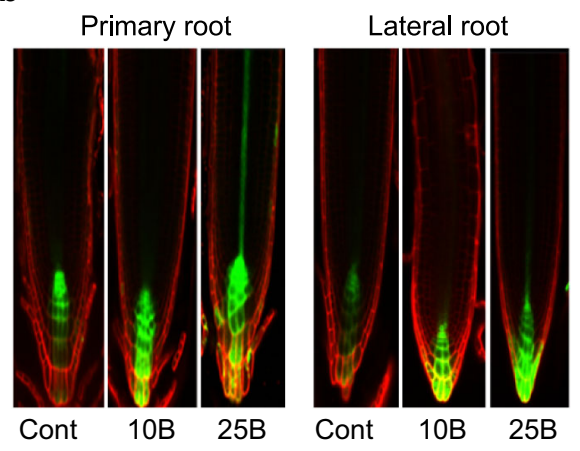

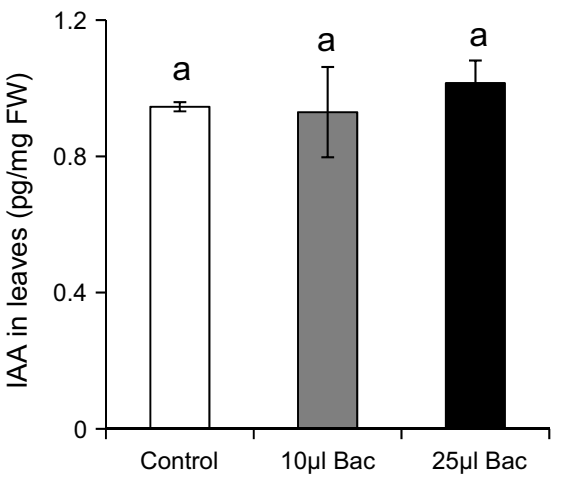

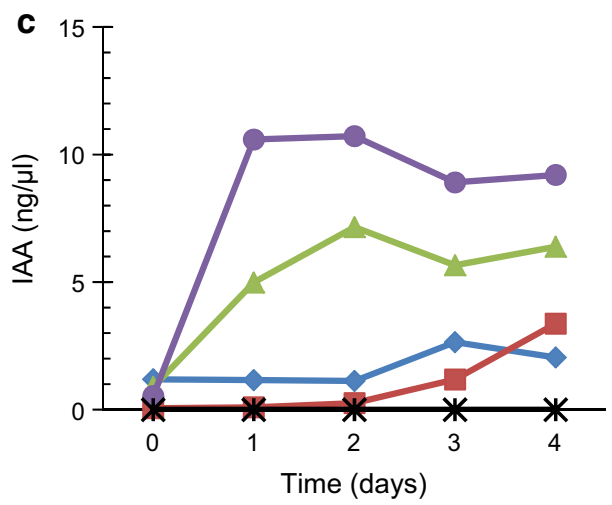

\section{Effect of bacterial exudates on root architecture of Arabidopsis Col-0}

To further investigate the inhibition of the primary root growth observed after UCMB5113 inoculation, bacterial exudates were tested for their effects. Whole exudates as well as a lipopeptide enriched fraction were tested for their effects to approach the role of bacterial secondary metabolites for growth inhibition. Six-day-old Arabidopsis Col-0 seedlings were kept on $0.2 \times \mathrm{MS}$ agar plates and inoculated at $3 \mathrm{~cm}$ distance from the main root with bacterial exudates collected from days 2 to 6 of growth and a crude lipopeptide extract. It was observed that the root increasingly avoided the bacterial exudate from day 2 to 6 , but not the lipopeptide extract, although the effect was weaker compared to when the whole bacteria were used (Fig. 6a, b). The effects on lateral roots and root area were also much smaller or insignificant compared to when bacteria were used. Primary root growth retardation was also observed with auxin treatments (Fig. 6a, b) suggesting that the effects are not related to toxic secondary metabolites, but rather hormonal in nature. Fitness effects by lipopeptide treatment of Arabidopsis Col-0 were measured as seed parameters, where the number of siliques, seed size, and seed weight increased slightly and even more by a repeated lipopeptide treatment (Supplementary Fig. S1).

\section{Effect of exudate lipopeptide extract on growth of different Arabidopsis lines}

Lipopeptides have been suggested to prime ISR through JA signaling in other systems. To test effects on plant growth of the lipopeptide extract made from the Bacillus exudate, roots of Arabidopsis plants were treated with the extract and grown on $0.5 \times \mathrm{MS}$ agar plates. Crude-extract-treated Arabidopsis wild-type (Col-0) plants showed both larger leaves and increased root branching compared to the controls, while no effects on primary roots were observed (Fig. 7a). We then compared the effects on growth in signaling mutants, where coil-16 and nprl-1 showed similar growth promotion as the wild-type plants. While the jarl mutant showed increased root branching (Fig. 7a, b), no effects on leaves occurred compared to plants treated with methanol or water (Fig. 7a). We further tested the growth promotion ability on the above ground tissues of plants grown on soil. Similar results were observed for the leaf size of soil grown wild-type (Col-0), coil-16 and npr11 plants compared to the MS agar grown plants (Supplementary Fig. S2). The time of flowering varied among the treatments and mutants. Compared to the wild type, coil16 and jarl plants showed earlier bolting and the plants were often taller compared to water and methanol treatment (Supplementary Fig. S3). In the case of npr1, Bacillus treatment resulted in shorter but flowering plants. 
Table 1 Gibberellin analysis of Arabidopsis thaliana Col-0 roots. Gibberellin levels were determined after 6 days of co-cultivation with UCMB5113

\begin{tabular}{|c|c|c|c|}
\hline \multirow[t]{3}{*}{ Gibberellin } & \multicolumn{3}{|c|}{ Gibberellin content ( $\mathrm{pg} / \mathrm{mg}$ of root fresh weight) } \\
\hline & \multirow[t]{2}{*}{ Control } & \multicolumn{2}{|c|}{ Inoculation (dose dependent) } \\
\hline & & $10 \mu 1$ & $25 \mu \mathrm{l}$ \\
\hline GAi & $0.17 \pm 0.02^{\mathrm{b}}$ & $0.31 \pm 0.02^{\mathrm{a}}$ & $0.15 \pm 0.02^{\mathrm{b}}$ \\
\hline $\mathrm{GA}_{3}$ & $0.78 \pm 0.16^{\mathrm{a}}$ & $0.39 \pm 0.14^{\mathrm{a}}$ & $0.66 \pm 0.09^{\mathrm{a}}$ \\
\hline $\mathrm{GA}_{4}$ & $0.016 \pm 0.007^{\mathrm{a}}$ & $0.004 \pm 0.001^{\mathrm{a}}$ & $0.008 \pm 0.002^{\mathrm{a}}$ \\
\hline $\mathrm{GA}_{5}$ & $6.23 \pm 0.74^{\mathrm{a}}$ & $4.97 \pm 0.74^{\mathrm{a}}$ & $4.64 \pm 0.89^{\mathrm{a}}$ \\
\hline $\mathrm{GA}_{6}$ & $0.02 \pm 0.01^{\mathrm{a}}$ & $0.05 \pm 0.02^{\mathrm{a}}$ & $0.05 \pm 0.02^{\mathrm{a}}$ \\
\hline $\mathrm{GA}_{7}$ & $0.23 \pm 0.02^{\mathrm{a}}$ & $0.03 \pm 0.00^{\mathrm{b}}$ & $0.05 \pm 0.01^{\mathrm{b}}$ \\
\hline $\mathrm{GA}_{8}$ & $1.53 \pm 0.16^{\mathrm{a}}$ & $1.81 \pm 0.19^{\mathrm{a}}$ & $0.88 \pm 0.04^{\mathrm{b}}$ \\
\hline $\mathrm{GA}_{9}$ & $1.55 \pm 0.28^{\mathrm{a}}$ & $2.02 \pm 0.25^{\mathrm{a}}$ & $2.29 \pm 0.45^{\mathrm{a}}$ \\
\hline GA13 & $0.07 \pm 0.02^{\mathrm{a}}$ & $0.15 \pm 0.01^{\mathrm{a}}$ & $0.04 \pm 0.01^{\mathrm{a}}$ \\
\hline $\mathrm{GAi}_{5}$ & $4.99 \pm 0.71^{\mathrm{b}}$ & $5.73 \pm 0.46^{\mathrm{b}}$ & $17.3 \pm 1.79^{\mathrm{a}}$ \\
\hline GA19 & $0.25 \pm 0.04^{\mathrm{b}}$ & $0.20 \pm 0.02^{\mathrm{b}}$ & $1.31 \pm 0.25^{\mathrm{a}}$ \\
\hline GA20 & $0.64 \pm 0.05^{\mathrm{a}}$ & $0.83 \pm 0.10^{\mathrm{a}}$ & $0.25 \pm 0.01^{\mathrm{b}}$ \\
\hline $\mathrm{GA}_{24}$ & $1.28 \pm 0.25^{\mathrm{b}}$ & $2.47 \pm 0.33^{\mathrm{a}}$ & $2.61 \pm 0.22^{\mathrm{a}}$ \\
\hline GA29 & $6.42 \pm 0.46^{\mathrm{b}}$ & $0.72 \pm 0.15^{\mathrm{a}}$ & $2.28 \pm 0.07^{\mathrm{a}}$ \\
\hline GA34 & $0.23 \pm 0.13^{\mathrm{b}}$ & $0.77 \pm 0.06^{\mathrm{a}}$ & $0.77 \pm 0.20^{\mathrm{a}}$ \\
\hline GA44 & $0.88 \pm 0.17^{\mathrm{a}}$ & $1.34 \pm 0.06^{\mathrm{a}}$ & $1.36 \pm 0.24^{\mathrm{a}}$ \\
\hline $\mathrm{GA}_{5} \mathrm{i}$ & $18.17 \pm 1.09^{\mathrm{a}}$ & $24.15 \pm 3.44^{\mathrm{a}}$ & $19.59 \pm 1.82^{\mathrm{a}}$ \\
\hline $\mathrm{GA}_{53}$ & $5.10 \pm 1.02^{\mathrm{a}}$ & $2.91 \pm 0.33^{\mathrm{a}}$ & $0.46 \pm 0.06^{\mathrm{a}}$ \\
\hline Total & 48.6 & 48.9 & 54.6 \\
\hline
\end{tabular}

Treatments labelled with identical letters are not significant at $p<0.05$

\section{Discussion}

The rhizosphere is abundant with microorganisms that can strongly influence plant performance, for example, by modulating nutrient uptake and thereby either enhance or decrease nutrient availability. Although many studies have been concerned with the beneficial plant-microbe interaction, relatively, few have provided a more thorough description of the effects on the plant by the interaction when it involves PGPR (e.g., Desbrosses et al. 2009; Zamioudis et al. 2013). An inherent difficulty is to study the root architecture of plants that grow in soil. In this study, we used axenically grown Arabidopsis as a model system to investigate the effect on phenotypic properties, plant growth regulation, and root architecture by B. amyloliquefacienes UCMB5113 known to provide disease suppression (Danielsson et al. 2007; Sarosh et al. 2009).

A positive effect was observed with growth promotion for Arabidopsis after UCMB5113 treatment. After inoculation of bacteria, the growth of primary roots was similar in control and inoculated plants during the first 2 days. However, after 3 days of inoculation, a gradual reduction of primary root length but increased outgrowth and elongation of lateral roots was observed in inoculated plants as compared with control plants. This suggests that bacterial metabolites alter the root system and development of the plant by reducing the proliferative activity and growth of the primary root while stimulating premature differentiation of root hairs and lateral root formation. The analysis of cell division in primary root tips using a cyclin:Gus reporter line did not find a significant effect by UCMB5113 treatment, although there was a tendency for decreased number of dividing cells in inoculated samples. However, the detailed anatomy of the root tip needs to be further studied to characterize the effects at the cellular level, since the shape of the root tip is less elongated after UCMB5113 treatment. Previously, it has been shown that plant roots associated with microbes that release phytohormones affect root morphogenesis and result in overproduction of lateral roots and root hair (Persello-Cartieaux et al. 2003). IAA producing bacteria can inhibit root growth depending upon the dose of bacteria (Persello-Cartieaux et al. 2003) and such a reduced root elongation and increased shoot to root was demonstrated in sugar beet seedlings (Loper and Schroth 1986), and similar effects were reported for Brassica juncea, wheat, and Arabidopsis (Asghar et al. 2002; Khalid et al. 2004; Zamioudis et al. 2013). Auxin plays an important role in promoting cell division (Campanoni and Nick 2005), inhibits cell elongation, and increases the number of lateral roots and root hairs when in excess (Swarup et al. 2007). Our data on the DR5:Gus reporter line treated with UCMB5113 showed enhanced auxin response in the root cap, root meristem, and procambium of Arabidopsis roots. UCMB5113 was found to secrete IAA constitutively, and this production was also inducible and increased when bacteria were grown in the presence of root exudates and further stimulated by tryptophan, which has been demonstrated to be an IAA precursor in a related Bacillus strain (Idris et al. 2007). Treatment with a bacterial cell-free exudate on Arabidopsis seedlings resulted in reorientation of the main root that avoided growth towards the bacterial compounds. This demonstrates that UCMB5113 produces multiple diffusible compounds; some with auxin activity and that may interact with the auxin signaling pathways. It was demonstrated that three PGPR Pseudomonas strains varied in their production of auxins, where one strain that did not produce auxins still elevated Arabidopsis auxin responsive gene levels and resulted in a similar root phenotype as for UCMB5113 (Zamioudis et al. 2013). These results suggest that PGPR do not need to produce auxins to stimulate plant growth and that the effects on root architecture do not primarily involve PGPR auxins. Root development is a complex trait and involves multiple components, where certain transcription factors and miRNAs are some of the key regulators that may be affected as a result of PGPR action (Tian et al. 2014). 
Table 2 Gibberellin analysis of Arabidopsis thaliana Col-0 shoots. Gibberellin levels were determined after 6 days of cocultivation with UCMB5113

\begin{tabular}{|c|c|c|c|}
\hline \multirow[t]{3}{*}{ Gibberellin } & \multicolumn{3}{|c|}{ Gibberellin content ( $\mathrm{pg} / \mathrm{mg}$ of leaf fresh weight) } \\
\hline & \multirow[t]{2}{*}{ Control } & \multicolumn{2}{|c|}{ Inoculation (dose dependent) } \\
\hline & & $10 \mu \mathrm{l}$ & $25 \mu \mathrm{l}$ \\
\hline GAi & $0.14 \pm 0.01^{\mathrm{b}}$ & $0.40 \pm 0.10^{\mathrm{a}}$ & $0.17 \pm 0.06^{\mathrm{b}}$ \\
\hline $\mathrm{GA}_{3}$ & $0.68 \pm 0.14^{\mathrm{a}}$ & $0.87 \pm 0.11^{\mathrm{a}}$ & $0.82 \pm 0.10^{\mathrm{a}}$ \\
\hline $\mathrm{GA}_{4}$ & $0.0046 \pm 0.0008^{\mathrm{a}}$ & $0.0118 \pm 0.0047^{\mathrm{a}}$ & $0.0184 \pm 0.0073^{\mathrm{a}}$ \\
\hline $\mathrm{GA}_{5}$ & $4.28 \pm 0.74^{\mathrm{a}}$ & $4.12 \pm 0.21 \mathrm{a}$ & $1.68 \pm 0.23^{\mathrm{b}}$ \\
\hline $\mathrm{GA}_{6}$ & $0.031 \pm 0.011^{\mathrm{ab}}$ & $0.033 \pm 0.005^{\mathrm{ab}}$ & $0.014 \pm 0.002^{\mathrm{b}}$ \\
\hline $\mathrm{GA}_{7}$ & $0.15 \pm 0.03^{\mathrm{a}}$ & $0.13 \pm 0.02^{\mathrm{a}}$ & $0.10 \pm 0.01^{\mathrm{a}}$ \\
\hline $\mathrm{GA}_{8}$ & $1.58 \pm 0.21^{\mathrm{b}}$ & $3.39 \pm 0.18^{\mathrm{a}}$ & $1.24 \pm 0.05^{\mathrm{b}}$ \\
\hline $\mathrm{GA}_{9}$ & $1.56 \pm 0.27^{\mathrm{a}}$ & $0.70 \pm 0.07^{\mathrm{b}}$ & $0.40 \pm 0.09^{\mathrm{b}}$ \\
\hline GA13 & $0.038 \pm 0.003^{\mathrm{b}}$ & $0.045 \pm 0.005^{\mathrm{b}}$ & $0.236 \pm 0.005^{\mathrm{a}}$ \\
\hline $\mathrm{GAi}_{5}$ & $6.59 \pm 0.89^{\mathrm{b}}$ & $16.57 \pm 1.04^{\mathrm{a}}$ & $2.65 \pm 0.09^{c}$ \\
\hline GA19 & $0.56 \pm 0.03^{\mathrm{a}}$ & $0.18 \pm 0.03^{b}$ & $0.33 \pm 0.03^{\mathrm{c}}$ \\
\hline GA20 & $1.03 \pm 0.04^{\mathrm{a}}$ & $0.98 \pm 0.13^{\mathrm{a}}$ & $0.11 \pm 0.01^{\mathrm{b}}$ \\
\hline $\mathrm{GA}_{24}$ & $2.50 \pm 0.28^{\mathrm{a}}$ & $1.14 \pm 0.12^{\mathrm{b}}$ & $1.25 \pm 0.14^{\mathrm{b}}$ \\
\hline GA29 & $1.31 \pm 0.27^{\mathrm{a}}$ & $0.62 \pm 0.27^{\mathrm{b}}$ & $1.24 \pm 0.07^{\mathrm{ab}}$ \\
\hline GA34 & $0.73 \pm 0.25^{\mathrm{a}}$ & $0.63 \pm 0.09^{\mathrm{ab}}$ & $0.23 \pm 0.04^{\mathrm{b}}$ \\
\hline GA44 & $0.78 \pm 0.06^{\mathrm{c}}$ & $1.08 \pm 0.10^{\mathrm{b}}$ & $1.87 \pm 0.05^{\mathrm{a}}$ \\
\hline $\mathrm{GA}_{5} \mathrm{i}$ & $18.04 \pm 0.90^{\mathrm{a}}$ & $22.45 \pm 0.47^{\mathrm{c}}$ & $10.46 \pm 0.91^{\mathrm{b}}$ \\
\hline $\mathrm{GA}_{53}$ & $1.69 \pm 0.23^{\mathrm{b}}$ & $2.51 \pm 0.17^{\mathrm{a}}$ & $0.21 \pm 0.01^{\mathrm{c}}$ \\
\hline Total & 41.7 & 55.9 & 23.0 \\
\hline
\end{tabular}

Treatments labelled with identical letters are not significant at $p<0.05$

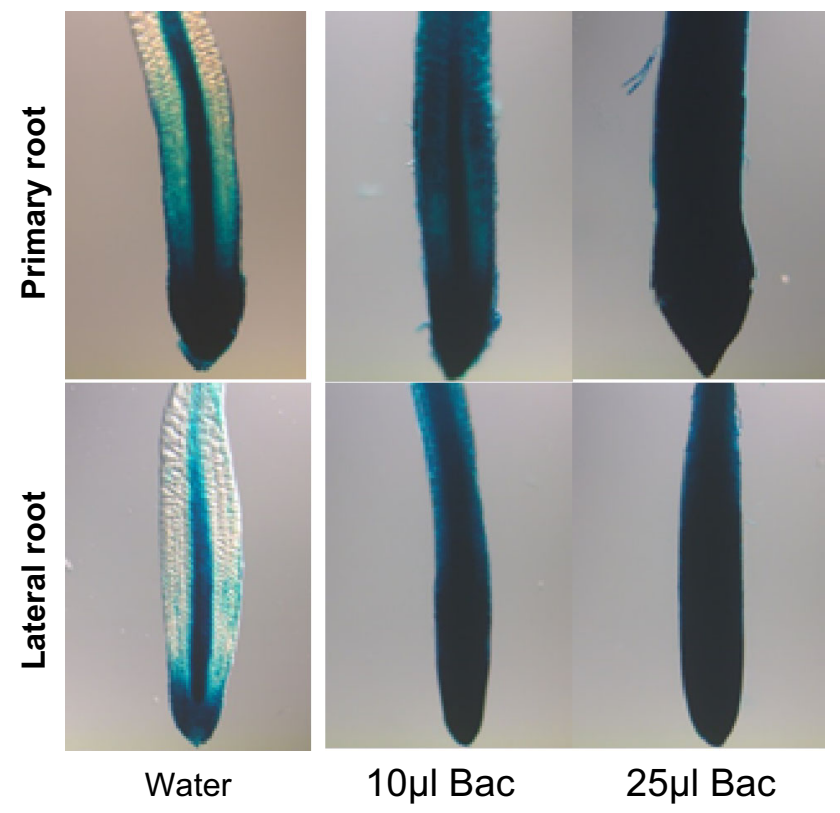

Fig. 4 Root expression of the cytokinin responsive reporter $\mathrm{Ar}$ r5:Gus. Five-day-old seedlings on $0.2 \times$ MS agar plates were treated with water or Bacillus UCMB5113 and analyzed 6 days later for expression of Arr5:Gus in primary or lateral roots
The analysis of GA in plants inoculated with UCMB5113 showed that bacteria affected the GA levels differently in roots and shoots in Arabidopsis seedlings after 6 days of co-cultivation compared to wild type. While total levels increased somewhat in roots after UCMB5113 treatment, the levels in shoots were almost halved. However, $\mathrm{GA}_{24}, \mathrm{GA}_{34}$, and $\mathrm{GA}_{15}, \mathrm{GA}_{19}, \mathrm{GA}_{24}, \mathrm{GA}_{34}$, and $\mathrm{GA}_{1}$, $\mathrm{GA}_{8}, \mathrm{GA}_{51}, \mathrm{GA}_{53}$, and $\mathrm{GA}_{15}$, and $\mathrm{GA}_{44}$, respectively, showed increased levels in root and shoot of Bacillusinoculated plants. GA production was found in rhizobacterial cultures of red pepper, where several Bacillus strains were found to stimulate growth and to produce different GAs (Joo et al. 2004). Our studies on Arr5:Gus transgenic marker with UCMB5113 enhanced expression of CK in root and indicates that $\mathrm{CK}$ metabolism is affected by UCMB5113 and probably involved in growth modulation. UCMB5113 could actively metabolize CKs as indicated by rapid disappearance of $\mathrm{CK}$ ribosides and $\mathrm{O}$-glucosides present in the medium. At the same time, rapid increases in $\mathrm{CK}$ bases occurred with receptor binding properties suggesting an active role in modulation of plant roots (Spíchal 2012). The interconversion of moderately biologically active CK ribosides into highly biologically active CK 
Table 3 Cytokinin levels in UCMB 5113 exudates

\begin{tabular}{|c|c|c|c|c|}
\hline \multirow[t]{2}{*}{ Sample/time } & \multicolumn{4}{|c|}{ Cytokinin content $(\mathrm{fmol} / \mu \mathrm{l})$} \\
\hline & $\mathrm{CK}-\mathrm{Ba}$ & CK-R & CK-Nuc & CK-Ogl \\
\hline \multicolumn{5}{|l|}{$\mathrm{LB}+5113$} \\
\hline T0 & $16.08 \pm 1.24^{\mathrm{c}}$ & $279.8 \pm 32.0^{\mathrm{a}}$ & $0.61 \pm 0.16^{\mathrm{b}}$ & $17.31 \pm 1.87^{\mathrm{a}}$ \\
\hline $\mathrm{T} 24$ & $146.4 \pm 17.8^{\mathrm{b}}$ & $5.46 \pm 1.19^{\mathrm{b}}$ & $3.42 \pm 0.63^{\mathrm{a}}$ & $0.38 \pm 0.06^{\mathrm{b}}$ \\
\hline $\mathrm{T} 72$ & $194.7 \pm 13.1^{\mathrm{a}}$ & $1.40 \pm 0.26^{\mathrm{b}}$ & $0.73 \pm 0.23^{\mathrm{b}}$ & $0.32 \pm 0.07^{\mathrm{b}}$ \\
\hline $\mathrm{T} 120$ & $152.4 \pm 16.9^{\mathrm{b}}$ & $3.91 \pm 0.99^{\mathrm{b}}$ & $0.63 \pm 0.13^{\mathrm{b}}$ & $0.25 \pm 0.02^{\mathrm{b}}$ \\
\hline \multicolumn{5}{|c|}{$\mathrm{LB}+5113+$ root exudate } \\
\hline T0 & $15.98 \pm 1.08^{\mathrm{c}}$ & $300.6 \pm 29.1^{\mathrm{a}}$ & $0.66 \pm 0.15^{\mathrm{b}}$ & $16.66 \pm 3.65^{\mathrm{a}}$ \\
\hline $\mathrm{T} 24$ & $167.0 \pm 13.9^{\mathrm{b}}$ & $9.45 \pm 1.22^{\mathrm{b}}$ & $1.80 \pm 0.29^{\mathrm{a}}$ & $0.21 \pm 0.02^{\mathrm{b}}$ \\
\hline $\mathrm{T} 72$ & $214.9 \pm 22.7^{\mathrm{a}}$ & $1.92 \pm 0.43^{\mathrm{b}}$ & $0.68 \pm 0.16^{\mathrm{b}}$ & $0.10 \pm 0.05^{\mathrm{b}}$ \\
\hline T120 & $205.4 \pm 25.9^{\mathrm{a}}$ & $3.08 \pm 0.86^{\mathrm{b}}$ & $0.39 \pm 0.04^{\mathrm{c}}$ & $0.06 \pm 0.02^{\mathrm{b}}$ \\
\hline \multicolumn{5}{|c|}{$\mathrm{LB}+$ root exudate } \\
\hline & $14.01 \pm 1.64$ & $292.4 \pm 43.9$ & $0.53 \pm 0.10$ & $18.66 \pm 3.36$ \\
\hline \multicolumn{5}{|l|}{ LB } \\
\hline & $12.91 \pm 1.88$ & $273.7 \pm 40.4$ & $0.50 \pm 0.13$ & $14.94 \pm 3.20$ \\
\hline
\end{tabular}

Total cytokinin bases (CK-Ba), cytokinin ribosides (CK-R), cytokinin nucleotides (CK-Nuc), and cytokinin O-glucosides (CK-Ogl) were measured in UCMB 5113 exudates at 0 (T0), 24 (T24), 72 (T72), and $120 \mathrm{~h}$ (T120) of continuous growth. Means and standard deviation of three biological samples and of each three technical replicates are shown

Treatments labelled with identical letters are not significant at $p<0.05$ bases coupled with the decreases of the inactive conjugated storage forms of CKs indicates that UCMB5113 is capable to stimulate plant growth. The ability of UCMB5113 to elevate both $\mathrm{CK}$ and auxin expression in roots, as reveled by use of reporter gene plants, indicates a complex effect on root growth. The key regulator SHY2, controlling meristem size and development, is stimulated by CK but repressed by auxin and also influenced by other hormones (Pacifici et al. 2015). Increased SHY2 activity due to a changed hormonal balance could be one factor that contributes to the arrested primary root growth caused by UCMB5113. The analysis of brassinosteroids showed a mixed pattern, where the level of different brassinosteroids in roots and shoot varied among the treatments. In roots, brassinolide, castasterone, and teasterone were increased by low amounts of UCMB5113, while in leaves, basal levels were generally higher and less affected but downregulated in the case of teasterone and typhasterol. The relatively profound changes and the tissue specific patterns still point to an important effect of UCMB5113 on these hormones and a role in the observed changes in growth.

In plants, the JA signaling pathways are often activated by plant growth-promoting microbes after root colonization (Van der Ent et al. 2009; Pieterse et al. 2012). The previous studies suggests that ethylene and JA signaling pathways may interfere in auxin transport and signaling with subsequent influence on root development and archi- tecture (Stepanova et al. 2007; Swarup et al. 2007). Our results revealed that the root structural effects of Arabidopsis caused by UCMB5113 are not dependent on the classical JA signaling pathway but involve other signals. The UCMB5113 total exudate fraction also caused root growth avoidance, while a lipopeptide fraction with antibiosis properties not gave these effects suggesting that the primary root inhibition effects are not due to toxic secondary metabolites but rather involves other factors. The effect on primary root growth by UCMB5113 exudate was lower than when intact bacteria were used. This can be a matter of differences in local concentration of secreted active compounds that the physical interaction with bacteria is needed or that the bacterial secretome change as a result of the plant interaction which calls for further studies.

The bacterial exudate added to roots stimulated plant growth as seen by increased leaf size and more extended root system of Arabidopsis Col-0 wild-type plants. The JA mutants coil-16 and jarl also responded by increased root growth, but only coil-16 showed increased leaf growth. Opposite effects were observed for the salicylic acid and ISR compromised nprl plants with increased leaf size, but no effects on root growth after addition of Bacillus exudates which indicates that living cells and transcriptional responses of the corresponding genes are needed for growth promotion. The UCMB5113 exudate also affected 

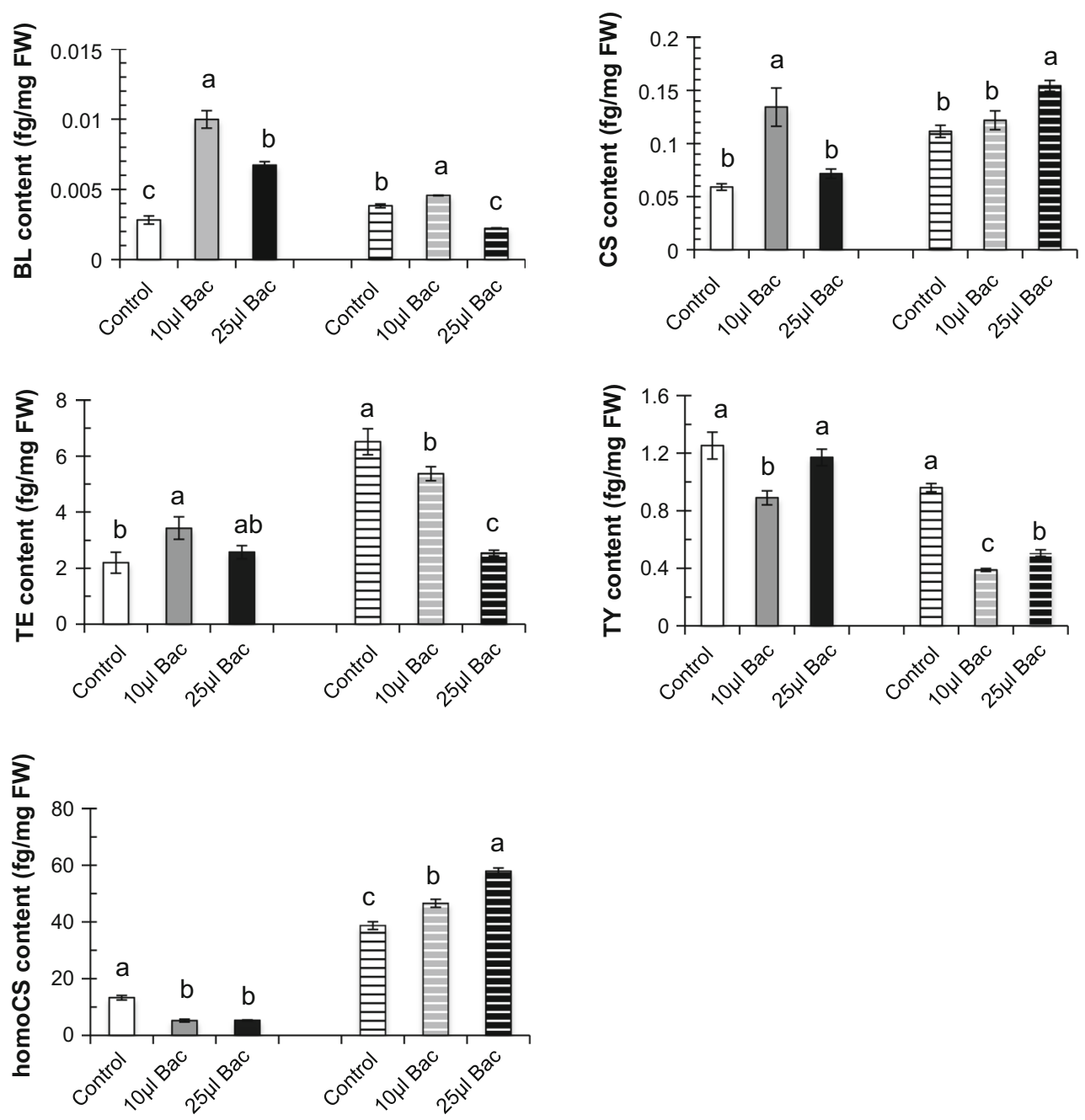

Fig. 5 Brassinosteroid analysis of UCMB5113 treated Arabidopsis. Five-day-old seedlings on $0.2 \times$ MS agar plates were treated with water or Bacillus UCMB5113 and analyzed 6 days later for brassinosteroid levels in roots and shoots (striped bars). The

the flowering phenotype of some lines with stunted or higher inflorescence structures. In this case, nprl plants were more stunted, while Col-0 were higher as well as coil-16 plants, but here, a solvent effect was also observed, where methanol gave some stimulation. It has been reported that salicylic acid deficiency stimulates leaf biomass and seed production (Abreu and Munné-Bosch 2009). On the other hand, plant responses to stress by JA signaling usually restrict plant growth (Hou et al. 2013). In our case, it seems like the lipopeptide fraction has the major effect on JA compromised plants indicating that other signals than JA are stimulated by the lipopeptide fraction-stimulating growth. There is no clear correlation between effects on growth and disease suppression against Alternaria (data not shown) among the Arabidopsis lines indicating that

brassinosteroids analyzed were brassinolide (BL), castasterone (CS), teasterone (TE), typhasterol (TY), and homocastasterone (homoCS). Values represent means and standard deviations $(n=4)$, where samples labelled with identical letters are not significant at $p<0.05$

Bacillus derived growth promotion does not operate through the same systems that improve stress tolerance of plants. Dependence on JA for bacterial primed ISR has been demonstrated for several other systems (Conrath 2011; Pieterse et al. 2012).

The data presented in this work provide further information of the beneficial plant-microbe interactions and impact of microorganisms on plants hormones, cellular, and root architecture development as well as the role of some signals. Exudates are complex mixtures of proteins and low molecular weight compounds with multiple functions. Root colonizing bacteria frequently form a biofilm at the rhizoplane that provide further functionality and may stimulate further interaction between the host and the microbe and also serve as a diffusion barrier (Vlamakis 

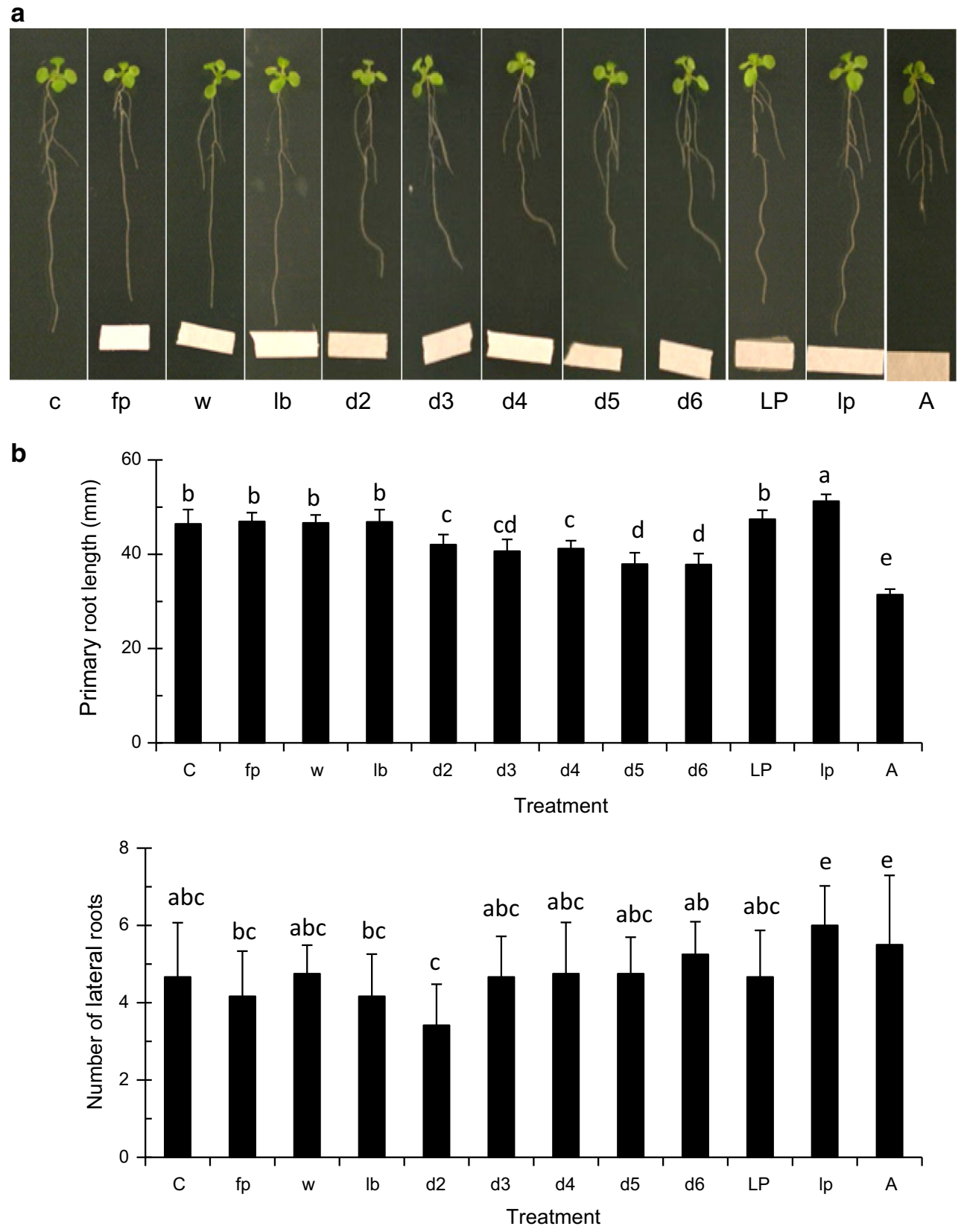

Fig. 6 Effect of Bacillus compounds on growth and development of A. thaliana Col-0. a One-week-old Arabidopsis seedlings were lined up on $0.2 \times$ MS agar plates. Bacillus UCMB5113 sterile filtrated culture supernatant from day 2 to 6 , crude lipopeptide fraction, or auxin were dropped on filter paper at $3 \mathrm{~cm}$ distance from the main root tip. At 6 days of post-inoculation, digital images were taken for the overall root analysis. Samples were control (c), filter paper (fp),

et al. 2013). The ability of UCMB5113 to form biosurfactants supporting biofilm formation is thus an important feature for root colonization. The interaction mechanisms in soil are unfortunately very difficult to study, but investigations using in vitro conditions with different model
$25 \mu$ volume of water (w), LB (lb), culture supernatants from day 2 (d2), day 3 (d3), day 4 (d4), day 5 (d5), day 6 (d6), crude lipopeptides (LP), $10 \times$ diluted crude lipopeptides (lp) synthetic auxin applied as $800 \mathrm{pg}$ (A). b Analysis of primary root length and total number of later roots deduced by use of the rhizo software. Values represent means and standard deviations $(n=16)$, where samples labelled with identical letters are not significant at $p<0.05$

systems can at least approach many of the molecular mechanisms behind plant growth promotion by PGPR and support development of useful microbial tools to support crop production and more bio-based production systems using beneficial microbes as an ecosystem service. 

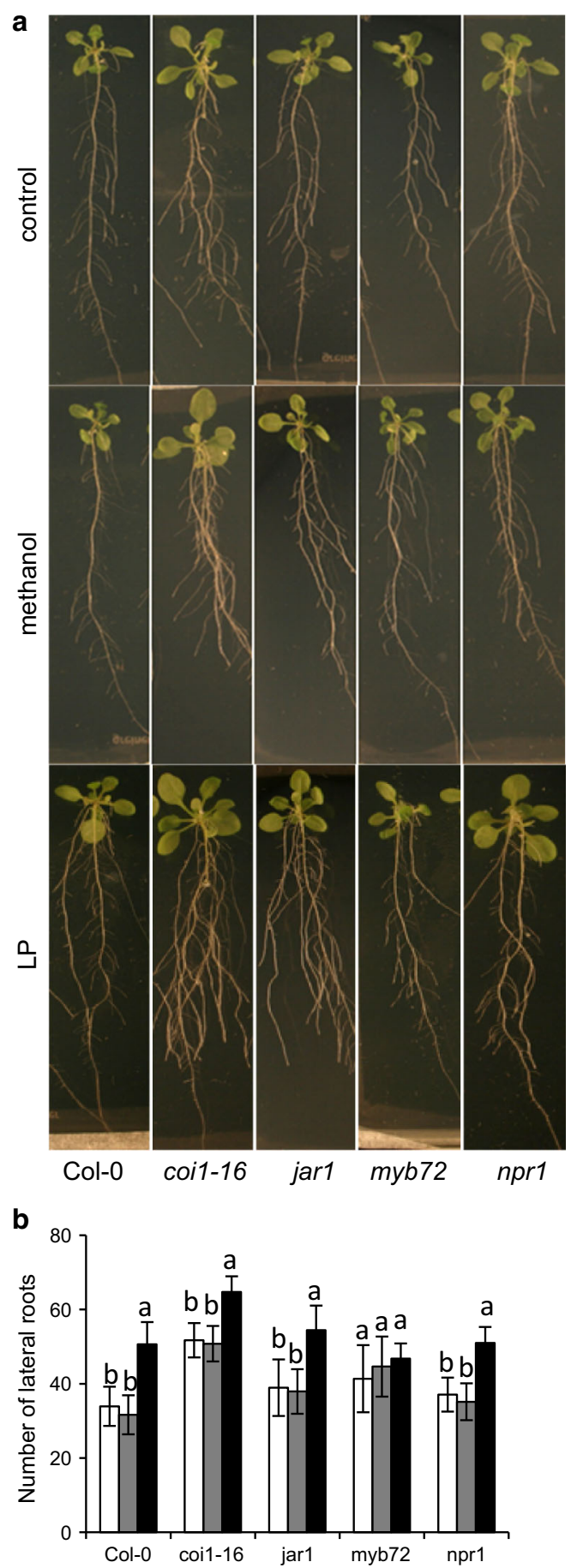

Fig. 7 Effect of crude lipopeptide compounds on growth and development of $A$. thaliana Col-0 wild type and mutants. Oneweek-old seedlings of $A$. thaliana Col-0 and the mutants coil-16, jarl, myb72, and nprl were treated on the roots with water, $5 \%$ methanol (solvent control), or enriched lipopeptide fraction (LP) and grown on $0.5 \times$ MS agar plates. Plants were analyzed after 10 days (a) and effects on total number of lateral roots measured after treatment with water (white bars), methanol (grey bars), or enriched lipopeptide fraction (LP) (black bars) (b). Values represent means and standard deviations $(n=16)$, where samples labelled with identical letters are not significant at $p<0.05$
Author contribution statement SA, SB, and JM conceived and designed research. SA, DT, JR, and ON conducted experiments. DT, JR, and ON performed the hormone analysis. DVP generated material for CK analysis. SA contributed with the other analysis. SA, DT, JR, and JM analyzed the data. SA wrote the first version of the manuscript. All authors read and approved the manuscript.

Acknowledgments These studies were supported by the Swedish Research Council for Environment, Agricultural Sciences, and Spatial Planning (FORMAS), Carl Tryggers Stiftelse, the Helge Ax:son Johnsons fond, and the Nilsson-Ehle fund. The authors also acknowledge financial support of Ministry of Education, Youth and Sports of the Czech Republic (LK21306 and LO 1204), Internal Grant Agency of Palacký University (PrF 2015-021), and Grant Agency of the Czech Republic (14-34792S). We thank Martin Palmqvist for skillful help with the confocal microscopy and Dimitris Kokoretsis for guidance on cyclin analysis. We are grateful to Dr. Laura GrenvilleBriggs for helpful comments on the manuscript. Sincere thanks to Andrea Novotná and Eva Hirnerová (Laboratory of Growth Regulators) for excellent technical assistance, Eva Sundberg (Dept of Plant Biology, SLU) for the DR5:GFP line and Annelie Carlsbecker (Dept. of Organismal Biology, Uppsala University) for Arr5:Gus, and $c y$ c1:Gus Arabidopsis lines.

\section{Compliance with ethical standards}

Conflict of interest The authors declare that they have no competing interests.

Open Access This article is distributed under the terms of the Creative Commons Attribution 4.0 International License (http://creative commons.org/licenses/by/4.0/), which permits unrestricted use, distribution, and reproduction in any medium, provided you give appropriate credit to the original author(s) and the source, provide a link to the Creative Commons license, and indicate if changes were made.

\section{References}

Abd El-Daim IA, Bejai S, Meijer J (2014) Improved heat stress tolerance of wheat seedlings by bacterial seed treatment. Plant Soil 379:337-350

Abreu ME, Munné-Bosch S (2009) Salicylic acid deficiency in NahG transgenic lines and sid 2 mutants increases seed yield in the annual plant Arabidopsis thaliana. J Exp Bot 60:1261-1271

Alexandre G (2010) Coupling metabolism and chemotaxis-dependent behaviours by energy taxis receptors. Microbiology 156:2283-2293

Antoniadi I, Plačková L, Simonovik B, Doležal K, Turnbull C, Ljung K, Novák O (2015) Cell-type specific cytokinin distribution within the Arabidopsis primary root apex. Plant Cell 27:1955-1967

Armengaud P, Zambaux K, Hills A, Sulpice R, Pattison RJ, Blatt MR, Amtmann A (2009) EZ-Rhizo: integrated software for the fast and accurate measurement of root system architecture. Plant $\mathbf{J}$ 57:945-956

Asghar HN, Zahir ZA, Arshad M, Khalid A (2002) Relationship between in vitro production of auxins by rhizobacteria and their growth-promoting activities in Brassica juncea L. Biol Fertil Soils 35:231-237 
Azevedo LB, van Zelm R, Leuven RSEW, Hendriks AJ, Huijbregts MAJ (2015) Combined ecological risks of nitrogen and phosphorus in European freshwaters. Environ Pollut 200:85-92

Badri DV, Vivanco JM (2009) Regulation and function of root exudates. Plant Cell Environ 32:666-681

Bastian F, Cohen A, Piccoli P, Luna V, Baraldi R, Botini R (1998) Production of indole-3-acetic acid and gibberellins A1 and A3 by Acetobacter diazotrophicus and Herbaspirillum seropedicae in chemically defined media. Plant Growth Regul 24:7-11

Blom D, Fabbri C, Connor EC, Schiestl FP, Klauser DR, Boller T, Eberl L, Weisskopf L (2011) Production of plant growth modulating volatiles is widespread among rhizosphere bacteria and strongly depends on culture conditions. Environ Microbiol 13:3047-3058

Boller T, Felix G (2009) A renaissance of elicitors: perception of microbe-associated molecular patterns and danger signals by pattern-recognition receptors. Annu Rev Plant Biol 60:379-406

Brown ME, Funk CC (2008) Climate-food security under climate change. Science 319:580-581

Campanoni P, Nick P (2005) Auxin-dependent cell division and cell elongation: 1-naphthaleneacetic acid and 2,4-dichlorophenoxyacetic acid activate different pathways. Plant Physiol 137:939-948

Choudhary DK, Johri BN (2009) Interactions of Bacillus spp. and plants-with special reference to induced systemic resistance (ISR). Microbiol Res 164:493-513

Claeys H, De Bodt S, Inzé D (2014) Gibberellins and DELLAs: central nodes in growth regulatory networks. Trends Plant Sci 19:231-239

Conrath U (2011) Molecular aspects of defence priming. Trends Plant Sci 16:524-531

Cramer GR, Urano K, Delrot S, Pezzotti M, Shinozaki K (2011) Effects of abiotic stress on plants: a systems biology perspective. BMC Plant Biol 11:163

D'Agostino IB, Deruère J, Kieber JJ (2000) Characterization of the response of the Arabidopsis response regulator gene family to cytokinin. Plant Physiol 124:1706-1717

Danielsson J, Reva O, Meijer J (2007) Protection of oilseed rape (Brassica napus) toward fungal pathogens by strains of plantassociated Bacillus amyloliquefaciens. Microb Ecol 54:134-140

Desbrosses G, Contesto C, Varoquaux F, Galland M, Touraine B (2009) PGPR-Arabidopsis interactions is a useful system to study signaling pathways involved in plant developmental control. Plant Signal Behav 4(4):319-321

Donnelly PM, Bonetta D, Tsukaya H, Dengler RE, Dengler NG (1999) Cell cycling and cell enlargement in developing leaves of Arabidopsis. Dev Biol 215:407-419

Gaillochet C, Daum G, Lohmann JU (2015) O cell, where art thou? The mechanisms of shoot meristem patterning. Curr Opin Plant Biol 23:91-97

Glickmann E, Dessaux Y (1995) A critical examination of the specificity of the Salkowski reagent for indolic compounds produced by phytopathogenic bacteria. Appl Environ Microbiol 61:793-796

Gutierrez-Manero FJ, Ramos-Solano B, Probanza A, Mehouachi J, Tadeo FR, Talon M (2001) The plant-growth-promoting rhizobacteria Bacillus pumilis and Bacillus licheniformis produce high amounts of physiologically active gibberellins. Physiol Plant 111:206-211

Hou X, Ding L, Yu H (2013) Crosstalk between GA and JA signaling mediates plant growth and defense. Plant Cell Rep 32:1067-1074

Howell SH, Lall S, Che P (2003) Cytokinins and shoot development. Trends Plant Sci 8:453-459

Idris EE, Iglesias DJ, Talon M, Borriss R (2007) Tryptophandependent production of indole-3-acetic acid (IAA) affects level of plant growth promotion by Bacillus amyloliquefaciens FZB42. Mol Plant Microbe Interact 20:619-626

Johansson AH, Bejai S, Niazi A, Manzoor S, Bongcam-Rudloff E, Meijer J (2014) Studies of plant colonisation by closely related Bacillus amyloliquefaciens biocontrol agents using strain specific quantitative PCR assays. Antonie Van Leeuwenhoek 106:1247-1257

Joo GJ, Kim YM, Lee IJ, Song KS, Rhee IK (2004) Growth promotion of red pepper plug seedlings and the production of gibberellins by Bacillus cereus, Bacillus macroides and Bacillus pumilus. Biotechnol Lett 26:487-491

Khalid A, Arshad M, Zahir ZA (2004) Screening plant growthpromoting rhizobacteria for improving growth and yield of wheat. J Appl Microbiol 96:473-480

Kim PI, Bai H, Bai D, Chae H, Chung S, Kim Y, Park R, Chi YT (2004) Purification and characterization of a lipopeptide produced by Bacillus thuringiensis CMB26. J Appl Microbiol 97:942-949

Loper JE, Schroth MN (1986) Influence of bacterial sources of indole3 -acetic acid in root elongation of sugar beet. Phytopathology 76:386-389

Lucy M, Reed E, Glick BR (2004) Applications of free living plant growth-promoting rhizobacteria. Antonie Leeuwenhoek Int J G $86: 1-25$

Martínez-Morales LJ, Soto-Urzúa L, Baca BE, Sánchez-Ahédo JA (2003) Indole-3-butyric acid (IBA) production in culture medium by wild strain Azospririllum brasilense. FEMS Microbiol Lett 228:167-173

Ortíz-Castro R, Contreras-Cornejo HA, Macías-Rodríguez L, LópezBucio J (2009) The role of microbial signals in plant growth and development. Plant Signal Behav 4:701-712

Pacifici E, Polverari L, Sabatini S (2015) Plant hormone cross-talk: the pivot of root growth. J Exp Bot 66:1113-1121

Pěnčík A, Rolčík J, Novák O, Magnus V, Barták P, Buchtík R, Salopek-Sondi B, Strnad M (2009) Isolation of novel indole-3acetic acid conjugates by immunoaffinity extraction. Talanta 80:651-655

Persello-Cartieaux F, Naussaume L, Robaglia C (2003) Tales from the underground: molecular plant-rhizobacteria interactions. Plant Cell Environ 26:189-199

Pieterse CMJ, Van der Does D, Zamioudis C, Leon-Reyes A, Van Wees SCM (2012) Hormonal modulation of plant immunity. Annu Rev Cell Dev Biol 28:489-521

Reva ON, Dixelius C, Meijer J, Priest FG (2004) Taxonomic characterization and plant colonizing abilities of some bacteria related to Bacillus amyloliquefaciens and Bacillus subtilis. FEMS Microbiol Ecol 48:249-259

Rittenberg D, Foster GL (1940) A new procedure for quantitative analysis by isotope dilution with application to the determination of amino acids and fatty acids. J Biol Chem 133:737-744

Rogers ED, Benfey PN (2014) Regulation of plant root system architecture: implications for crop advancement. Curr Opin Biotechnol 32:93-98

Ryu C-M, Farag MA, Hu CH, Reddy MS, Wei HX, Paré PW, Kloepper JW (2003) Bacterial volatiles promote growth in Arabidopsis. Proc Natl Acad Sci USA 100:4927-4932

Sarosh BR, Danielsson J, Meijer J (2009) Transcript profiling of oilseed rape (Brassica napus) primed for biocontrol differentiate genes involved in microbial interactions with beneficial Bacillus amyloliquefasciens from pathogenic Botrytis cinerea. Plant Mol Biol 70:31-45

Schneider CA, Rasband WS, Eliceiri KW (2012) NIH Image to ImageJ: 25 years of image analysis. Nature Meth 9:671-675

Spaepen S, Vanderleyden J, Remans R (2007) Indole-3-acetic in microbial and microorganism plant signaling. FEMS Microbiol Rev 31:425-448 
Spíchal L (2012) Cytokinins-recent news and views of evolutionally old molecules. Funct Plant Biol 39:267-284

Stepanova AN, Yun J, Likhacheva AV, Alonso JM (2007) Multilevel interactions between ethylene and auxin in Arabidopsis roots. Plant Cell 19:2169-2185

Suzuki N, Rivero RM, Shulaev V, Blumwald E, Mittler R (2014) Abiotic and biotic stress combinations. New Phytol 203:32-43

Svačinová J, Novák O, Plačková L, Lenobel R, Holík J, Strnad M, Doležal K (2012) A new approach for cytokinin isolation from Arabidopsis tissues using miniaturized purification: pipette tip solid-phase extraction. Plant Methods 8:17

Swarup R, Perry P, Hagenbeek D, Van Der Straeten D, Beemster GTS, Sandberg G, Bhalerao R, Ljung K, Bennett MJ (2007) Ethylene upregulates auxin biosynthesis in Arabidopsis seedlings to enhance inhibition of root cell elongation. Plant Cell 19:2186-2196

Thomma BPHJ, Eggermont K, Penninckx IAMA, Mauch-Mani B, Vogelsang R, Cammue BPA, Broekaert WF (1998) Separate jasmonate-dependent and salicylate-dependent defence response pathways in Arabidopsis are essential for resistance to distinct microbial pathogens. Proc Natl Acad Sci USA 95:15107-15111

Tian H, De Smet I, Ding Z (2014) Shaping a root system: regulating lateral versus primary root growth. Trends Plant Sci 19:426-431
Urbanova T, Tarkowska D, Novák O, Hedden P, Strnad M (2013) Analysis of gibberellins as free acids by ultra performance liquid chromatography-tandem mass spectrometry. Talanta 112:85-94

Vacheron J, Desbrosses G, Bouffaud ML, Touraine B, MoënneLoccoz Y, Muller D, Legendre L, Wisniewski-Dyé F, PrigentCombaret C (2013) Plant growth-promoting rhizobacteria and root system functioning. Front Plant Sci 4:356

Van der Ent S, Van Wess SCM, Pieterse CMJ (2009) Jasmonate signaling in plant interactions with resistance-inducing beneficial microbes. Phytochemistry 70:1581-1588

Vlamakis H, Chai Y, Beauregard P, Losick R, Kolter R (2013) Sticking together: building a biofilm the Bacillus subtilis way. Nat Rev Microbiol 11:157-168

Zamioudis C, Pieterse CMJ (2012) Modulation of host immunity by beneficial microbes. Mol Plant Microbe Interact 25:139-150

Zamioudis C, Mastranesti P, Dhonukshe P, Blilou I, Pieterse CM (2013) Unraveling root developmental programs initiated by beneficial Pseudomonas spp. bacteria. Plant Physiol 162:304-318

Zhu JY, Sae-Seaw J, Wang ZY (2013) Brassinosteroid signaling. Development 140:1615-1620 